\title{
COLLODION SKIN IN THE NEONATE DUE TO LAMELLAR ICHTHYOSIS
}

\author{
BY \\ H. V. L. FINLAY and J. P. BOUND \\ From the Paediatric Unit, Hillingdon Hospital, Middlesex
}

(RECEIVED FOR PUBLICATION FEBRUARY 11, 1952)

Some degree of mild superficial desquamation is a very common feature during the first week of life: it occurs in small flakes, sometimes affecting the entire body and especially the trunk. But, in the case to be described, the dorsum of the hands and feet was covered at birth by a layer of glossy, collodion-like skin which soon desquamated. This condition is of considerable rarity.

Perez (1880), in Chile, described an infant whom he had seen on the day after birth and whose skin was replaced by a cornified substance of uniform consistency except in the region of the flexures where it was much thinner. This gave the whole body a varnished appearance, and the armour-like covering limited the movement of most of the joints and also of the orbicularis muscles, producing an unpleasant facies. At the age of 6 weeks, after desquamating completely three or four times, the skin was functioning 'more or less normally'.

Kaposi (1895) described the condition of 'ichthyosis sebacea' or 'seborrhoea squamosa neonatorum', in which, a few hours after birth, the skin was brownish-red and shone like silk as if it had been varnished. This he attributed to an increased amount of vernix caseosa, which continued to be produced for the first few days of life, and encrusted the skin.

Grass and Torok (1895) reported an infant who was born with a dry, shining, brownish-yellow skin which they likened to collodion. When seen at 24 hours, the shining layer showed fissures, and along the edges of the fissures it was detached, revealing normal skin beneath. The infant died two days later from intracranial haemorrhage. Grass and Torok considered that their case corresponded to the condition described as ichthyosis sebacea and, by microscopical examination of pieces of membrane, they disproved Kaposi's view of the aetiology. The pieces of membrane were found to be composed of horny cells, and showed sebaceous cells in the regions of the mouths of sebaceous glands only. They proposed the name 'lamellar exfoliation of the newborn' for such cases. In their view the condition was an unusual variety of the physiological desquamation of the newborn in which the cells showed a greater coherence than normal and formed a horny envelope. The latter was analogous to the horny membrane which had been described in the embryos of certain animals, covering the hairs, and hence called the epitrichium.

Bowen (1895) pointed out that Grass and Torok's view was not quite correct. He had confirmed, in a study of over 50 human embryos, that there was in the epidermis an outer layer of cells histologically distinct from the horny layer. It was evidently homologous with the epitrichium and so had been called the epitrichial layer, consisting of large cells with round nuclei much larger than those of the epidermal layers beneath. Further, this epitrichial layer disappeared by the seventh month of foetal life over most parts of the body so that the normal desquamation occurring in the last few months and in the neonatal period was produced from the true horny layer. He suggested that cases such as the one described by Grass and Torok were due to the epitrichial layer persisting up to the time of birth. The true horny layer then desquamated in small scales after its outer covering had been lost. In a case which Bowen recorded the child at birth was completely covered from head to foot by a thin, perfectly smooth membrane resembling paraffin paper. After this membrane had peeled off in large strips at the age of 5 weeks, a process of slow scaling continued for many months. The skin became ' almost normal' just before the child died of diphtheria about the age of 1 year. There was no family history of a similar condition.

Brauns (1896), suggesting the name 'superdesquamatio membranacea', described a baby aged 3 weeks with a similar appearance at birth, but scaling had largely cleared up by the age of 2 weeks.

Bonnet and Gaillard (1919), favouring the name 
'collodion-like lamellar desquamation of the newborn ', summarized the findings in two cases in which desquamation lasted several days after birth. Both mothers were syphilitic, and these authors favoured syphilis as the cause, although there were no other signs of this condition in the children.

Dean (1921) published a case, which he labelled ' congenital ichthyosis', though this diagnosis was probably incorrect. Desquamation continued for two months after birth before the skin became normal. It is of interest that two children of the maternal grandmother (the child's mother and aunt) had shown a similar appearance at birth: their skins were normal when examined by Dean. Both parents of the child gave a negative Wassermann reaction.

Under the title of maladie collodionnée, Coffin (1939) presented a 6-months-old male infant, first seen within a day or two of birth, with the appearance of having been dipped in a bath of collodion. Following the local application of oil, desquamation occurred in large shreds. On the face and limbs this was complete by the fifteenth day: elsewhere the skin desquamated twice and the supple pink skin, left after the first time, rapidly took on a collodion appearance again. The further desquamation which then occurred was almost completed by the age of 6 months. Histological examination of a shred proved normal. There was no sign of syphilis, and no family history of a similar skin condition.

Tanissa (1949) reported an infant, who, at the age of 4 days, had a generalized shining, varnished surface like a bladder of collodion, particularly on the thorax, hands and feet. In places on the forearms and legs the skin was scaly and slightly erythematous. A less severely affected younger brother of this child was described at the age of 22 days (Tanissa and Nunes, 1950) with a collodion covering of an earthy colour, in process of desquamation. Information is as yet lacking as to the subsequent progress of these children, who were described as cases of lamellar desquamation of the newborn.

More recently Hy (1950) has published an excellent photograph of a case of generalized collodion skin, under the title of "lamellar desquamation of the newborn', but no clinical details were given.

The foregoing account includes the cases of possible lamellar ichthyosis which have been found in the available literature. Several cases of true congenital ichthyosis are on record, however, which have shown a similar collodion-like appearance at birth, for example, those of Seitz (1936), Thibaut (1937, 1946) and Trefzer (1942). Indeed, among the first to use the descriptive term 'collodion' were Hallopeau and Watelet (1892) and their case showed typical ichthyosis 11 years later (Thibaut, 1937).

\section{Case Report}

C.G., a girl, the second child, was born by normal delivery in Hillingdon Hospital on December 24, 1950. The birth weight was $7 \mathrm{lb} .4 \mathrm{oz}$. and the infant cried well at birth. The mother's blood Wassermann reaction was negative at the seventh month of pregnancy. There was no known history of a skin abnormality in early infancy on either the father's or the mother's side of the family. The child's older brother, born on August 25, 1949, had never shown any skin abnormality.

The striking feature, even at the time of delivery, was the appearance of the skin over the dorsum of the hands, fingers, feet and toes. These areas were covered by a continuous pellicle with a clear, brightly shining surface of yellowish tint, strongly resembling collodion. This could be moved freely over the subcutaneous tissues. Although this abnormality could be seen also around the wrists and ankles, the palms and soles were not affected and the skin over the remainder of the body was normal.

General physical examination on the following day showed a normal heart with well expanded lungs. The liver was of normal size and the spleen not palpable. The skull circumference was 141 in. and there were no signs of cerebral irritation.

At the age of 2 days, the peripheral portions of this ' collodion skin ' had begun to separate, leaving normal skin below. Over a small portion of one foot, where the abnormal collodion skin had been forcibly removed, there was a raw bleeding area.

At the age of 4 days fissuring appeared, especially over the hands (Figs. 1 and 2). On the following day, on the suggestion of Dr. M. C. Joseph, a biopsy was performed on the dorsum of the right foot. This skin section showed parakeratosis-the cells of the stratum corneum retaining their nuclei: There was, however, a well-marked stratum granulosum with a line of separation between it and the stratum corneum. The rete mucosum was thicker than normal (Fig. 3). These features should be compared with a section of normal skin from the dorsum of one foot of an infant who died from asphyxia at the age of 3 days (Fig. 4).

As the fissuring and desquamation progressed, the effects of trauma were minimized by keeping the tissues soft by the frequent application of eucerin. By the ninth day, large areas of desquamation had occurred and apparently normal skin was left behind. The biopsy incision healed rapidly. The child, having regained her birth weight, was sent home on the tenth day and followed up thereafter at the outpatient clinic. Desquamation had entirely ceased by the end of the third week, and from that time onwards the texture of the skin remained normal. Breast feeding was continued for six months. The child's blood Wassermann reaction was negative at the age of 7 months. When last seen at the age of $\mathbf{2 0}$ months, the skin of the hands and feet, 


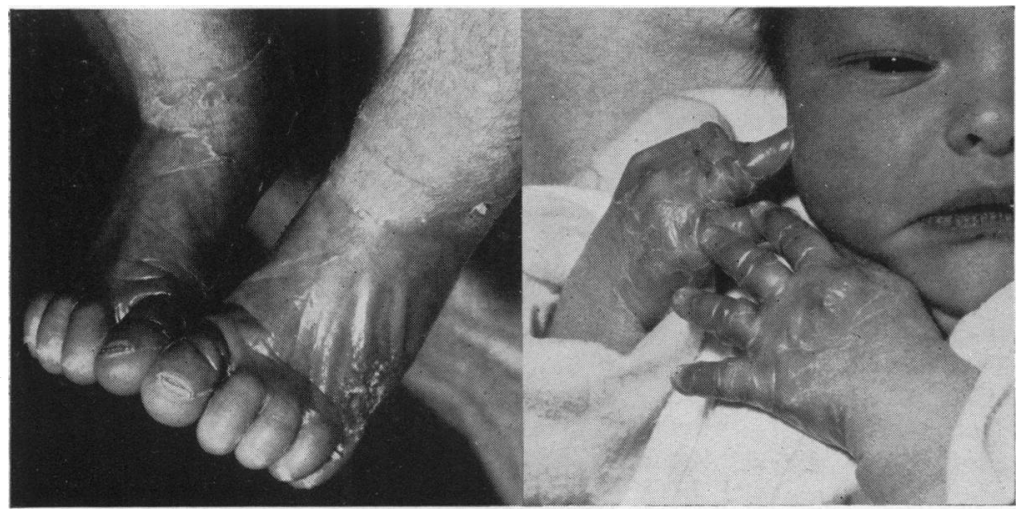

Fig. 1.-Feet at the age of 4 days, showing collodion skin.

as over the remainder of the body, was of normal texture and the infant was thriving.

\section{Three Groups of Published Cases of Collodion-like Skin in Neonates}

It will thus be seen that the published cases of children showing a collodion-like skin at birth fall into three main groups.

(1) The rare true cases of lamellar desquamation of the newborn (lamellar ichthyosis): these children are left with entirely normal skin once the desquamation has been completed, as in the present case.

(2) The apparently more common cases of ichthyosis congenita which present a 'collodion skin' at birth: these cases would tend to support the conjecture put forward by Cockayne (1933) that this type of congenital ichthyosis and lamellar desquamation of the newborn are closely allied conditions. In congenital ichthyosis, if the epitrichial layer is affected in addition to the true horny layer, the appearance at birth will resemble lamellar desquamation: but the skin, although it may improve strikingly, never becomes normal and the ichthyosis persists. The collodion skin in such cases usually involves the whole body. Cockayne has also pointed out (Ellis, 1936) that redness of the skin was common in congenital ichthyosis, a feature not usually present in true lamellar ichthyosis.
(3) Those cases of collodion skin which have been described during the early months of infancy, but about which we have no information as to subsequent progress: many of them were doubtless examples of ichthyosis congenita. It should be noted that Tanissa and Nunes (1950) use the term lamellar desquamation of the newborn to cover cases of collodion skin which either clear completely or go on to show one of the forms of ichthyosis.
Fig. 2.-Hands at the age of 4 days showing marked fissuring in the abnormal skin.

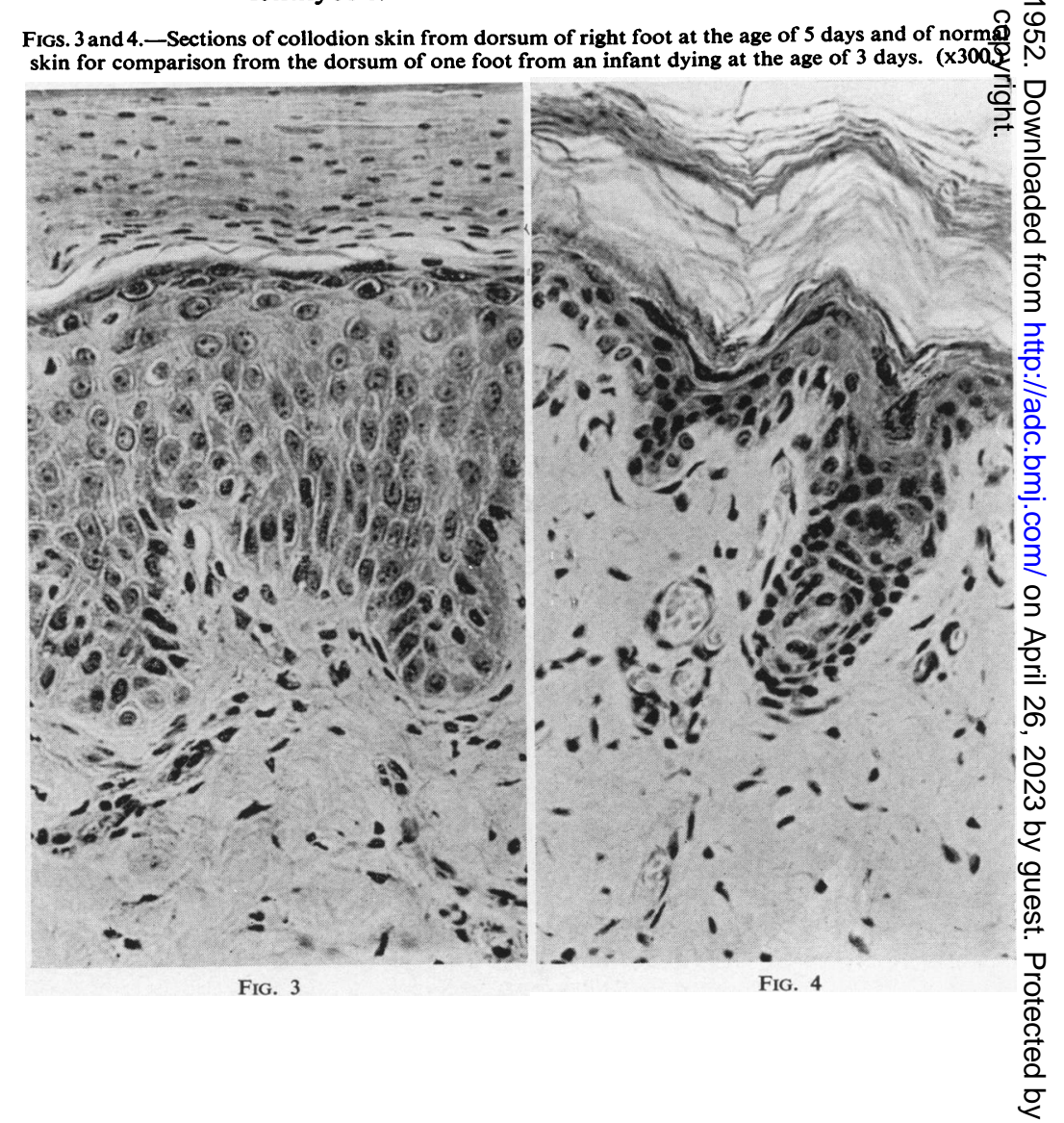


Lamellar Desquamation of the Newborn (Lamellar Ichthyosis)

In this condition the child is partially or entirely covered at birth with a shining, glossy, yellowish skin, resembling collodion or oiled paper, which soon cracks and desquamates in large sheets. Our case shows that only parts of the skin may be affected. Whether or not the skin below is left in a state of mild desquamation which gradually subsides, it finally returns to normal. The general vitality of the infant is unimpaired.

Little is known of the aetiology. There is usually no association with syphilis. It has been suggested that this rare and peculiar condition is an inherited abnormality. In only one instance, however, has more than one case in a family been recorded, that of Dean (1921), but the cases described by Tanissa and Nunes may provide another example. Auspitz's (1869) case has been cited as an example of familial lamellar ichthyosis, but the infant's skin at birth was described as dark brown, almost black, dry and rough. At the age of 13 months the scalp, back and chest showed a powdery white flakiness, and the case was in all probability one of ichthyosis congenita.

The close relation to ichthyosis congenita has been noted. It has been suggested that lamellar desquamation is the result of a similar disturbance which is confined to the epitrichial layer of the foetal skin and results in its persistence up to the time of birth, producing the appearance described above. This would explain why normal skin is left when this layer has dried and desquamated.

We would therefore agree with Cockayne (1933) in saying that:

\footnotetext{
' the transition from typical lamellar ichthyosis to the mildest variety of ichthyosis congenita is very gradual, and it is difficult to draw a line between them, but for the present it seems advisable to place them in different categories, though the division may prove to be an artificial one.'
}

If a case is first seen when desquamation has been under way for some days, the diagnosis may not be easy for, at this stage, Ritter's exfoliative dermatitis and Leiner's erythrodermia desquamativa may be simulated. Prolonged observation of a case, throughout the first year of life at least, is necessary to rule out the possible merging into, or onset of, a chronic ichthyotic state. A search of the literature has failed to reveal cases of collodion skin involving only localized parts of the body, as in the case here reported.
The surprising feature of the skin section, as seen in Fig. 3, is the well-marked stratum granulosum even in the presence of a parakeratotic stratum corneum. The line of separation to be seen just superficial to the stratum granulosum may not be entirely an artefact. It suggests the onset of true desquamation, with the stratum granulosum about to produce a normal stratum corneum, and this would accord with the clinical course. Too much stress should not be laid on the abnormal degree of thickness of the rete mucosum which tends to vary considerably in normal individuals.

\section{Summary}

A case of collodion skin due to lamellar desquamation of the newborn, affecting only the dorsum of the hands, fingers, feet and toes, is described in an otherwise normal infant. The condition proved benign and entirely normal skin remained once the collodion skin had desquamated.

Reference is made to the literature on the subject. The published cases of collodion skin in the neonate fall into three groups. (1) Those due to lamellar desquamation of the newborn ("lamellar ichthyosis '), which are eventually left with normal skin. (2) Those due to ichthyosis congenita: in these the skin may improve but never returns completely to normal. (3) Those in which definite allocation to one of the above groups is impossible because there was an insufficient period of recorded observation.

We wish to thank Dr. F. J. V. Jenner for his helpful advice in this case. Professor G. H. Percival has kindly guided us in the interpretation of the skin sections, for the special preparation of which we are indebted to Dr. H. Rogers. The photography and photomicrography are the work of Mr. E. Stride.

\section{REFERENCES}

Auspitz, H. (1869). Arch. Derm. Syph., Berl., 1, 253.

Bonnet, L. M. and Gaillard, - (1919), Lyon méd., 128, 616.

Bowen, J. T. (1895). J. cutan. Dis., 13, 485.

Bowen, J. T. (1895). J. cutan. Dis.,

Brauns, H. (1896). Derm. Z., 3, 343. Appendages, p. 159 . London.

Coffin, M. (1939). Bull. Soc. Pédiat., Paris, 37, 337.

Dean, C. H. (1921). J. Amer. med. Ass., 77, 465.

Ellis, R. W. B. (1936). Proc. roy. Soc. Med., 29, 748.

Grass, J. and Torok, L (1895). Ann. Derm. Syph., Paris, 3 ser., 6 104.

Hallopeau, - . and Watelet, - . (1892). Ibid., 3, 149.

Hy, - (1950). lbid., 8 ser., 10, 656-B, Fig. 196.

Kaposi, M. (1895). Pathology and Treatment of Diseases of the Skin, p. 125. London.

Perez, M. (1880). Rev. méd., Chili. Quoted in Petit, H. (1880). Progr méd, Paris, 1 ser., $8,524$.

Seitz, R. P. (1936). Calif. west. Med., 44, 500.

Seitz, R. P. (1936). Calif. west. Med., 44,

Tanissa, A. (1949), Gaz. méd. port., 2, 435 .

Thibaut, D. (1937). Bull. Soc. frans. Derm. Syph., 44, 1840.

(1946). Ann. Derm. Syph., Paris, 8 ser., 6, 489

$\overrightarrow{T r e f z e r, ~ C . ~(1942) . ~ A n n . ~ p a e d i a t ., ~ B a s e l, ~ 158, ~} 120$. 